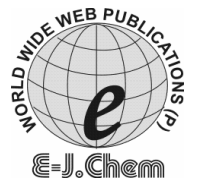

http://www.e-journals.net

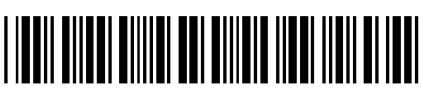

ISSN: 0973-4945; CODEN ECJHAO

E-Journal of Chemistry

2008, 5(S1), 969-979.

\title{
Review
}

\section{Synthesis, Characterization and Coordinating Behaviour of Aminoalcohol Complexes with Transition Metals}

\author{
K MAJID ${ }^{*}$, R MUSHTAQ and S.AHMAD \\ Department of Chemistry, National Institute of Technology, \\ Hazratbal, Srinagar- (J\&K), 190006. \\ kowsarmajid@yahoo.co.in
}

Received 23 November 2007; Accepted 20 January 2008

\begin{abstract}
The complexation of aminoalcohols with various transition metal and metal complexes have long and varied history. Since these complexes have found applications in various fields, the coordinating behaviour of these complexes should be investigated more precisely, in view of contradictory reports regarding coordinating behaviour of aminoalcohols with transition metals. This article is a review of findings of various investigations carried out from time to time.
\end{abstract}

Keywords: Aminoalcohols, Monoethanolamine, Diethanolamine, Triethanolamine, Complexation,

\section{Introduction}

Ethanol amines commonly known as 'aminoalcohols' were prepared in 1860 by 'Wurtz' from ethylene chlorohydrins and aqueous ammonia. It was only towards the end of $19^{\text {th }}$ century that ethanolamine mixture was separated into its mono-, di-, and triethanolamine components (mea, dea and tea) and was achieved by fractional distillation. Because of their basic nitrogen atom and the hydroxyl group, the chemical properties resemble those of both amines and alcohols. Monoethanolamine is the strongest of the three bases. The bifunctional nature of ethanolamines enables them to serve a variety of commercial applications such as inhibitors, surfactants, gas purification and herbicides ${ }^{1}$ Ethanolamines are the versatile ligands that readily form coordination compounds with almost all metal ions and behave as $\mathrm{N}$ and $\mathrm{O}$-donor ligands. The transition metal complexes of ethanolamines were synthesized by Sen- Dotson ${ }^{2}$ and Brannon et $\mathrm{al}^{3}$. Here monoethanolamine act both as monodentate and bidentate ligands ${ }^{4}$. Homo and heterobimettalic ethanolaminate derivatives of a number of metals have also been reported recently ${ }^{5-8}$. The complexation of ethanolamines with various 
transition metals has been studied since eighteenth century. The coordination chemistry of aminoalcohols with metal ions deserves further study because they play important role in nature, for example, in harmones ${ }^{9-10}$ and in aminosugars ${ }^{11-12}$. Very interesting but contradictory reports by various researchers from time to time make the investigation still interesting. For example, for the development and utilization of renewable energy sources, recently $\mathrm{Fe}$ (III)/Fe(II)-tea complex has found applications ${ }^{13}$ which ensure that these complexes can show potential for various industrial and technological applications. The preliminary investigation shows that Fe(III)tea/Fe(II)-tea couple is electrochemically promising as negative redox couple for redox flow battery ${ }^{14-15}$. Here we report the review of various studies of these aminoalcohol complexes.

\section{Complexation of aminoalcohols with cupric ions}

The complexes of mea, dea- and tea, with copper have been studied by potentiometeric, conductometric and spectophotometric methods by C W Davies and B N Patel in $1968^{16}$. The $\mathrm{Cu}$ :ligand ratio in case of mea and dea was found to be 1:1 and 1:2 respectively but only 1:1 for tea. The cupric salts react with mea, dea and tea to form a non-conducting complex. The hydroxyl group of all the three ethanolamines when coordinated to copper show markedly acid properties and forms an uncharged complex. The uncharged complex formed cannot react further in case of mea, whereas in case of dea and tea, they react further to form an anion by loosing further hydrogen. The inability of the mea to form the anion at high $\mathrm{pH}$ is explained by the absence of dissociable hydrogens in the stable $\mathrm{CuM}_{2}$ complex. The complex formation of $\mathrm{Cu}$ (II) with mea and dea in the aqueous solution has also been studied by means of ESR spectroscopy, using ESR titration method by $\mathrm{R}$ Tauler and E Casassas in 1986 , at $25^{\circ} \mathrm{C}$ and $1.0 \mathrm{M}$ ionic strength, to overcome the inefficiency of potentiometeric method. ${ }^{17}$ The method provides the simultaneous determinations of the stability constants of the formed species and of their formed ESR spectra. The four complex species with different stoichiometries were detected and their relative stabilities were also calculated. From the results obtained, deprotonation of the hydroxyl group and formation of stable chelate rings were proposed. At high $\mathrm{pH}$, when small amount of copper was added to the solution containing mea and dea in excess, amino groups were deprotonated and a release of two protons per atom of $\mathrm{Cu}$ (II) was observed. The fact is consistant with the formation of species containing two ligand molecules and having suffered the further deprotonation, which should come from the bonded water molecules or from the bonded hydroxyl groups of the ligands. In case of $\mathrm{Cu}$ (II) complexes of mea and dea, dimerization was not observed because the copper is complexed by two molecules of ligand before the deprotonation of the attached hydroxyl groups take place, therefore preventing the formation of two consecutive oxygen bridges, while with that of tea, it dimerises, as dimerization involves the formation of two consecutive oxygen bridges between the two metal ions, each of them attached to both oxygen atoms. ${ }^{18}$ Therefore complexation of copper with the tea shows that it acts as a multidentate ligand and coordinates via $\mathrm{N}$ and $\mathrm{O}$ atoms, forming a five membered ring while as mea and dea act as bidentate ligand via $\mathrm{N}$ and $\mathrm{O}$ and also results in the formation of stable ring. G.T.Amirov et al. in 1975 came with the crystal structure of dihydroxo bis (mea) copper (II) in order to understand the coordination of mea to metal in its complexes ${ }^{19}$ The complex $\left[\mathrm{Cu}(\mathrm{OH})_{2}\left(\mathrm{H}_{2} \mathrm{NCH}_{2} \mathrm{CH}_{2} \mathrm{OH}\right)_{2}\right] 2 \mathrm{H}_{2} \mathrm{O}$ crystallizes in the monoclinic system and forms lamellar rhomb-shaped blue crystals. The lattice parameters determined by the oscillation, rotation and Weissenberg $\left(\lambda_{\mathrm{Cu}}\right)$ methods are as follows; $a=8.90(4), b=12.33(5), c=7.15(3) \mathrm{A}^{\circ}, \beta=100.0(5)^{\circ}, \mathrm{v}=772.9 \mathrm{~A}^{\circ 3}, \mathrm{M}=255.6, \mathrm{Z}=2, \mathrm{~d}_{\text {calc }}$ $=1.10 \mathrm{~g} / \mathrm{cm}^{3}$. The systematic extinction of the reflections corresponds to the space group $\mathrm{p} 21 \mathrm{c}$. The structure was interpreted by the heavy atom method. The crystal structure consists of isolated complexes which are joined to one another by weak vanderwalls forces ${ }^{19}$ (Figure 1). 


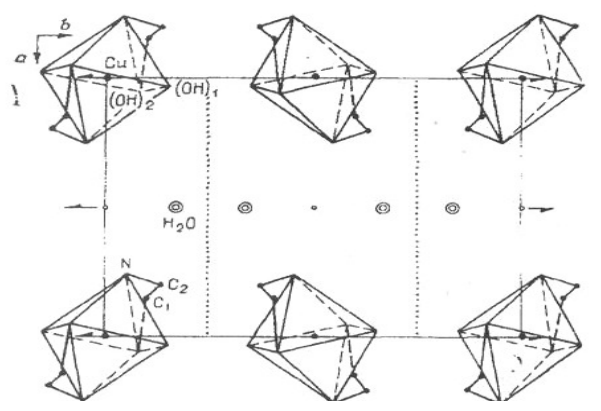

Figure 1. Projection of the structure on the xy plane

Here mea is coordinated to copper atom through nitrogen and oxygen simultaneously, that is, the coordination of copper is octahedral ${ }^{19}$ (Figure .2).

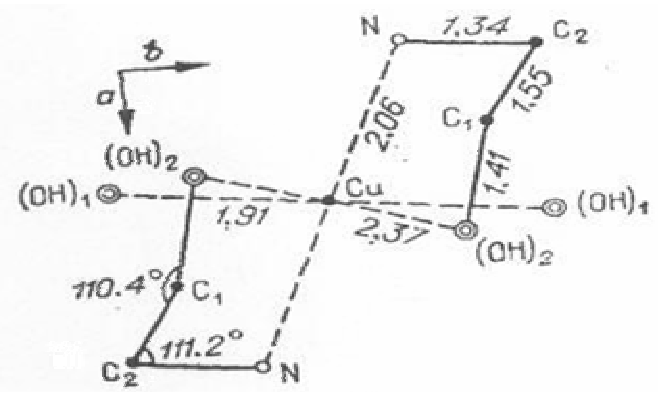

Figure 2. Projection of the molecule on the 001 plane

The structure also contains two water molecules which do not form the part of coordination polyhedra of copper and merely connect the individual isolated complexes by weak molecular hydrogen bonds in the direction of the a - axis. It was concluded that the weak bonding in the structure of the isolated groups in the [100] direction explains the lamellar habit of the crystals and the perfect cleavage along $\{100\}$.

\section{Complexation of $\mathrm{Ni}(\mathrm{II})$ and $\mathrm{Co}(\mathrm{II})$ theophyllinate complexes with mea}

Thermal, magnetic, FTIR and XRD study of Ni(II) and Co(II) theophyllinato complexes of mea were studied in 1998 by J Madarazs and his co-workers. ${ }^{20}$ Two theophyllinato complexes of $\mathrm{Co}(\mathrm{II})$ and $\mathrm{Ni}(\mathrm{II})$ with formula $\left[\mathrm{Co}(\mathrm{th})_{2}(\mathrm{ea})_{2}\right]$ and $\left[\mathrm{Ni}(\mathrm{th})_{2}(\mathrm{ea})_{2}\right]$ respectively were synthesized containing mea. Comprehensive FTIR spectroscopy, powder XRD, magnetic and thermal studies on these mixed ligand complexes have been carried out to get structural information. The FTIR spectra and the XRD pattern of the obtained complexes with the same ligands are strikingly similar. The FTIR spectra of the corresponding Co and Ni compounds are hardly distinguishable. Furthermore the XRD peak positions of the pairs with same ligand composition are also very close to each other. The FTIR and XRD peaks ${ }^{20}$ are shown in Figure $3 \& 4$.

On the basis of FTIR, XRD and thermal analysis, the assumption of two bidentate ethanolamine ligands supports an octahedral inner coordination sphere. However more decisive magnetic studies were carried out to prove their octahedral configuration. So far as magnetism is concerned, both the complexes are found to be paramagnetic. $\mu_{\text {eff }}$ for $\left[\mathrm{Co}(\mathrm{th})_{2}(\mathrm{ea})_{2}\right]$ and $\left[\mathrm{Ni}(\mathrm{th})_{2}(\mathrm{ea})_{2}\right]$ is 5.07 and 3.19 respectively. The magnetic moments of the complexes were calculated as per the following equation;

$$
\mu=2.828(\mathrm{~T} \chi \mathrm{mol}) \frac{1}{2} \text {. }
$$




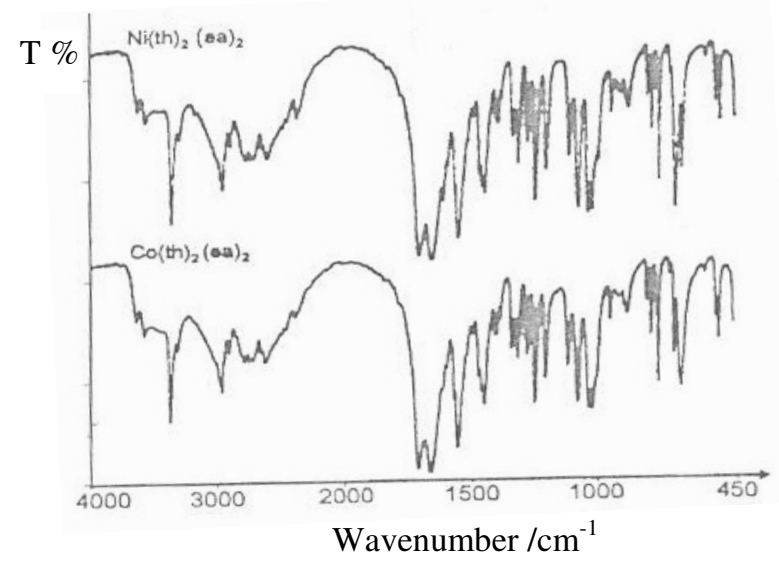

Figure 3. FTIR spectra of $\left[\mathrm{Co}(\text { th })_{2}(\mathrm{ea})_{2}\right]$ and $\left[\mathrm{Ni}(\mathrm{th})_{2}(\mathrm{ea})_{2}\right]$

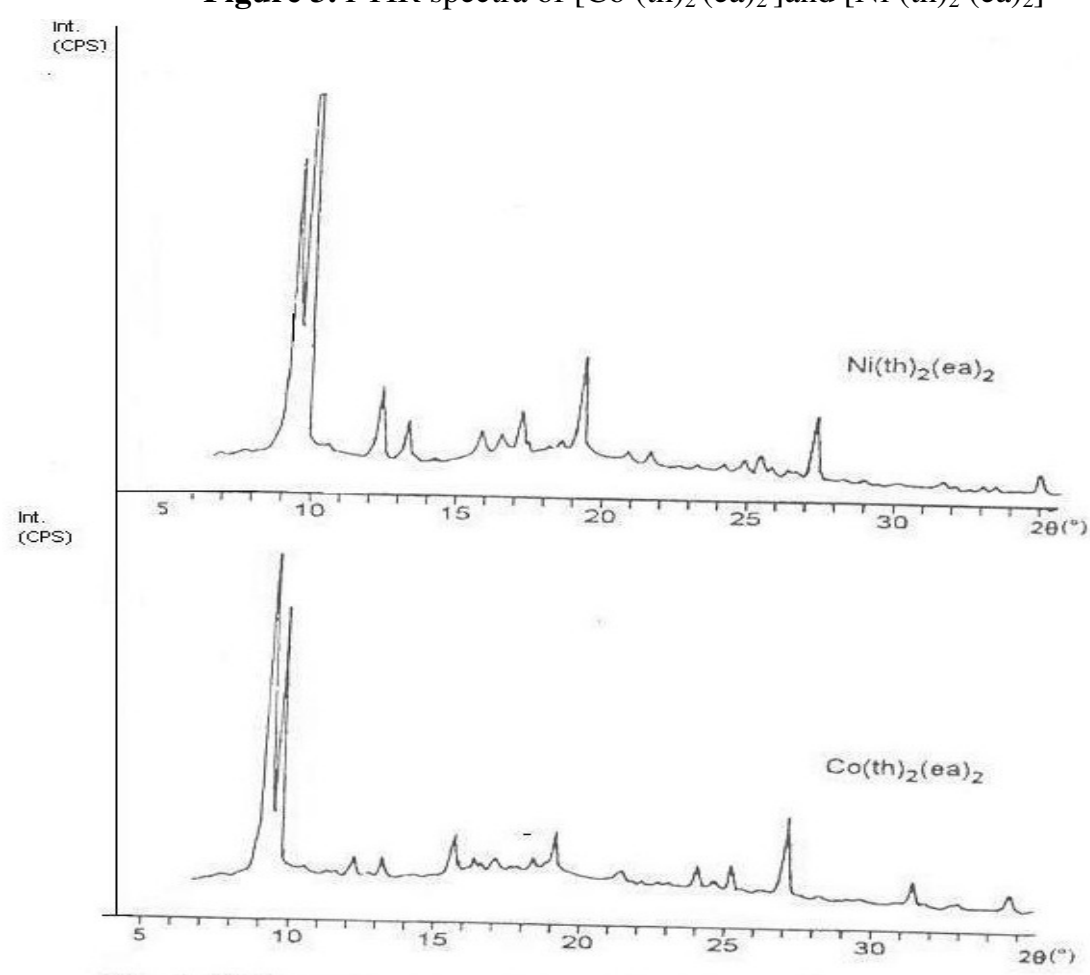

Figure 4. XRD patterns of $\left[\mathrm{Co}(\mathrm{th})_{2}(\mathrm{ea})_{2}\right]$ and $\left[\mathrm{Ni}(\mathrm{th})_{2}(\mathrm{ea})_{2}\right]$

The obtained magnetic moments show that the investigated compounds are high spin complexes of $\mathrm{Co}$ or $\mathrm{Ni}$ with 2 or 3 unpaired electrons. For a high spin octahedral cobalt complex a magnetic moment of 5.2 or somewhat lower is expected. Deviation from octahedral geometry decreases the $\mu_{\text {eff }}$ value. Taking into account the measured magnetic moments, it is concluded that $\left[\mathrm{Co}(\mathrm{th})_{2}(\mathrm{ea})_{2}\right]$ has a distorted octahedral geometry. In general, different $\mu_{\text {eff }}$ values could be expected for octahedral, square planar or tetrahedral stereochemistry of $\mathrm{Ni}$ (II) complexes. The square planar nickel complexes are diamagnetic $\left(\mu_{\text {eff }}=0\right)$. In case of octahedral complex, the expected magnetic 
moment is about $10 \%$ higher than the spin only value $(\mu=2.83)$. The observed value $\mu_{\text {eff }}$ for $\left[\mathrm{Ni}(\mathrm{th})_{2}(\mathrm{ea})_{2}\right]$ is 3.19 and a very distorted octahedron can be suggested for this. Monoethanolamine may act as a bidentate ligand and its $\mathrm{O}$ atom is stronger donor atom than the oxygen atom of water. Thus, it is not surprising that in the $\left[\mathrm{Co}(\mathrm{th})_{2}(\mathrm{ea})_{2}\right]$ complex a distorted octahedral coordination sphere with bidentate aminoalcohol ligands can be found. Their reciprocal molar susceptibility values are linearly dependent on temperature in accordance with the Curie law. This indicates that no metal-metal interaction occurs in the complexes, that is, metal centres are far enough from each other in the solid matrix. Complexes with mea show octahedral coordination, indicating partially bidentate feature of mea ligands. However no sufficient information is available to describe the exact spatial configuration of mea complexes of $\mathrm{Co}$ (II) and $\mathrm{Ni}$ (II).

\section{Complexation of metal thiocyanate complexes with dea and tea}

In the year 2001, A Karadag et al. reported the synthesis, spectra and thermal reactivity of novel $\mathrm{Co}(\mathrm{II}), \mathrm{Ni}(\mathrm{II}), \mathrm{Cu}(\mathrm{II}), \mathrm{Zn}(\mathrm{II})$ thiocyanate complexes with dea and tea with single crystal structure of the bis( $\mu$-diethanolaminato)bis (isothiocyanato) dicopper(II) complex $\left[\mathrm{Cu}_{2}(\mu \text {-dea })_{2}(\mathrm{NCS})_{2}\right]^{21}$ Characterization was carried out with various spectroscopic techniques. The results indicate that the $\mathrm{Co}(\mathrm{II})$ and $\mathrm{Cu}(\mathrm{II})$ complexes of dea are dimeric while other complexes of dea and all the tea are mononuclear. Dimeric compositions are achieved by alkoxo- bridges, and require deprotonation of one of the ethanolic groups of the diethanolamine ligand in order to compensate for the positive charges of metal ions. Dimeric structures of these complexes were also evidenced from thermal analysis and single crystal $\mathrm{X}$-ray analysis. In the mononuclear complexes, the dea acts as a bidentate ligand through its nitrogen and oxygen of the ethanolic group, while as tea behaves as a tri podal and tridentate $\mathrm{N}, \mathrm{O}, \mathrm{O}^{\prime}$ donor ligand. The structure of the $\mathrm{Ni}(\mathrm{II})$ complexes with tea differs from other tea complexes. Deprotonation of tea occurs in the $\mathrm{Co}(\mathrm{II})$ and $\mathrm{Zn}(\mathrm{II})$, and results in the composition of [M(tea)(NCS)]. The Ni(II) complex contains one neutral tea molecule and two NCS ligands. Evidence for the deprotonation of tea also came from single crystal X-ray analysis of these complexes. However the structural data was not good enough, due to the severe disorder occurred in the crystals. Microanalyses conformed the 2:2:2 metal: tea: NCS stoichiometric for the dimeric complexes, and 1:2:2 for the monomeric dea complexes and 1:1:1 for tea complexes. The magnetic moments of both the complexes of dea and tea were measured at room temperature. The metal complexes show high spin configuration. The magnetic moments agree well with the coordination geometry around the metal ions and the calculated values of the spin only magnetic moments. The $\mathrm{Cu}$ (II) complex of dea exhibit significantly high magnetic moment which may be a result of its doubly oxygen- bridged dimeric structure. It is reported that oxygen-bridged $\mathrm{Cu}$ (II) complexes are known to show subnormal magnetic moments due to super- exchange interaction. The metal complexes were also subjected to thermal decomposition process and it was found that both the dea and tea ligands are degraded and evolved thermally. Their degradation is not complete under nitrogen and results in the formation of a solid intermediate consisting of a metal, thiocyanate anion and some oxygen from the amines. Because of the complexity of the thermal decomposition process it was impossible to identify the intermediates, although in some cases IR spectroscopy was used. Thermo analytical data show that the tea complexes exhibit higher thermal stability than those of corresponding dea complexes as the initial decomposition temperatures are taken as a measure of thermal stability. This may be explained by the bond strength between the metal and the ligand, since the tea ligand acts as a tridentate ligand and form much stable complexes. The molecular structure of the doubly oxygen bridged dimeric $\mathrm{Cu}(\mathrm{II})$ complex of diethanolamine $\left[\mathrm{Cu}_{2}(\mu \text {-dea })_{2}(\mathrm{NCS})_{2}\right]$ (Figure 5$)^{21}$. 


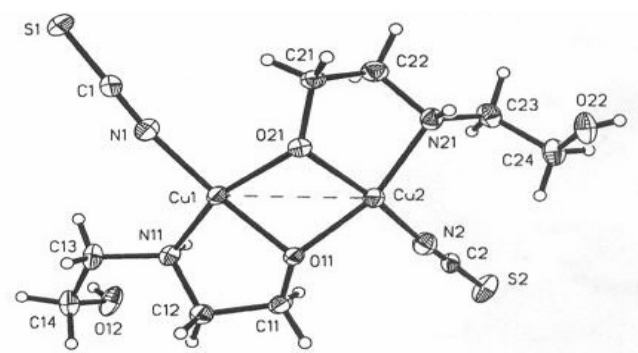

Figure 5. Molecular structure of $\left[\mathrm{Cu}_{2}(\mu \text {-dea })_{2}(\mathrm{NCS})_{2}\right]$ with the atom numbering scheme. The displacement ellipsoids are drawn at the $50 \%$ propability level and $\mathrm{H}$ atoms are shown as small circles of arbitrary radii ${ }^{21}$.

The complex is binuclear and each copper ion is four coordinated. The copper ions have two ethanolaminate oxygen bridges. The - $\mathrm{Cu}-\mathrm{O}-\mathrm{Cu}-\mathrm{O}$ - bridging group is planner. In the complex dea ligand is in the deprotonated form by loosing one of the ethanolic $\mathrm{H}$ and act as a bidentate donor through its nitrogen and deprotonated oxygen. Therefore in case of $\mathrm{Cu}$ (II) complex, the centrosymmetric binuclear complexes contains two strongly distorted square pyramidally coordinated copper ions bound together by two alkoxo bridges. The bridging oxygen is a deprotonated oxygen of the ethanolic group of dea. The dea ligand also coordinates to the $\mathrm{Cu}$ (II) ions through its nitrogen, while other ethanolic group does not involve in coordination. The thiocyanate anion coordinates to the $\mathrm{Cu}(\mathrm{II})$ ion with its nitrogen. In the mononuclear complexes, dea acts as a bidentate ligand through its nitrogen and the oxygen of the ethanolic group. The metal complexes of dea and tea with NCS may be considered as analogues of Werner type clathrates containing bi and tridentate amines and possess ability for inclusion of a small organic molecule. In other series of theophyllinato copper(II) complexes containing amine ligands, the structural effects of changing from mea to dea is examined. A new mixed ligand copper(II) complex has been synthesized as a model compound from aqueous solutions of copper sulphate, theophylline and dea. Its distinct structure has been determined by single X-ray diffraction by Janos Madarazs et al. ${ }^{22}$ in the year 2000. The centro symmetric binuclear complex contains two strongly distorted square pyramidally or pseudo- octahedrally coordinated copper ions bound together by two alkoxo-bridges. The bridging $\mathrm{O}$ is deprotonated oxygen of the monoalcoholate formed from dea. According to the ESR and the magnetic measurements, the two copper atoms are antiferromagnetically coupled.

\section{Complexation of Thallium(III) with tea}

The binuclear thallium (III) complexes of complexes of tea were studied by M R Udupa et al. ${ }^{23}$ in 1979.Tea $\left(\mathrm{H}_{3}\right.$ TEA $)$ is basically a tetradentate ligand and forms a variety of complexes with transition and representative metals. Though the alcoholic protons in tea are not acidic, this facilitates deprotonation resulting in the anionic metal complexes. The coordinated alkoxide groups may further form additional bonds through the oxygen bridges to give polynuclear complexes. The preparation, thermal behaviour, X-ray powder data and spectral characteristics of a $\mathrm{Tl}(\mathrm{III})$ complex of tea, $\mathrm{Tl}_{2}$ (HTEA) (TEA)Cl are reported.

\section{Complexation of tea with $\mathrm{Ni}, \mathrm{Sc}, \mathrm{Y}, \mathrm{Fe}, \mathrm{Zn}, \mathrm{Cd}, \mathrm{Pb}$ and $\mathrm{Bi}$}

In $1995 \mathrm{~J} \mathrm{G}$ Verkade studied the synthesis and complexes were prepared by the reaction of tea and the salt in a suitable solvent ${ }^{24}$. The complex formed are generally less soluble than the corresponding parent salts, while $\mathrm{Zn}(\mathrm{TEA})_{2} \mathrm{Br}_{2}$ and $\mathrm{Bi}(\mathrm{TEA})_{2} \mathrm{Cl}_{3}$ are not soluble in any 
common solvent. The complexes were characterized by ${ }^{1} \mathrm{H}$ and ${ }^{13} \mathrm{C}$ NMR spectroscopy except for $\mathrm{Fe}(\mathrm{TEA})_{2} \mathrm{Cl}_{3}$ which gave no useful information in its ${ }^{1} \mathrm{H}$ and $\mathrm{NMR}$ spectrum owing to its paramagnetic nature. The ${ }^{13} \mathrm{C}$ NMR spectrum revealed two somewhat broadened peaks for the $\mathrm{OCH}_{2}$ and $\mathrm{NCH}$ carbons. The structures of $\mathrm{Y}(\mathrm{TEA})_{2}\left(\mathrm{ClO}_{4}\right)_{3} \cdot 3 \mathrm{C}_{5} \mathrm{H}_{5} \mathrm{~N}$ and $\mathrm{Cd}(\mathrm{TEA})_{2}\left(\mathrm{NO}_{3}\right)_{2}$, determined by $\mathrm{X}$-ray diffraction unexpectedly revealed eight coordinate metals in both cases. Both the structures adopt a distorted hexagonal bipyramidal configuration in which the atoms in the hexagonal plane alternately fall above and below the plane. The unit cell of $\mathrm{Cd}(\mathrm{TEA})_{2}\left(\mathrm{NO}_{3}\right)_{2}$ and $\mathrm{Y}(\mathrm{TEA})_{2}\left(\mathrm{ClO}_{4}\right)_{3} \cdot 3 \mathrm{C}_{5} \mathrm{H}_{5} \mathrm{~N}$ (Figure 6, 7) ${ }^{24}$.

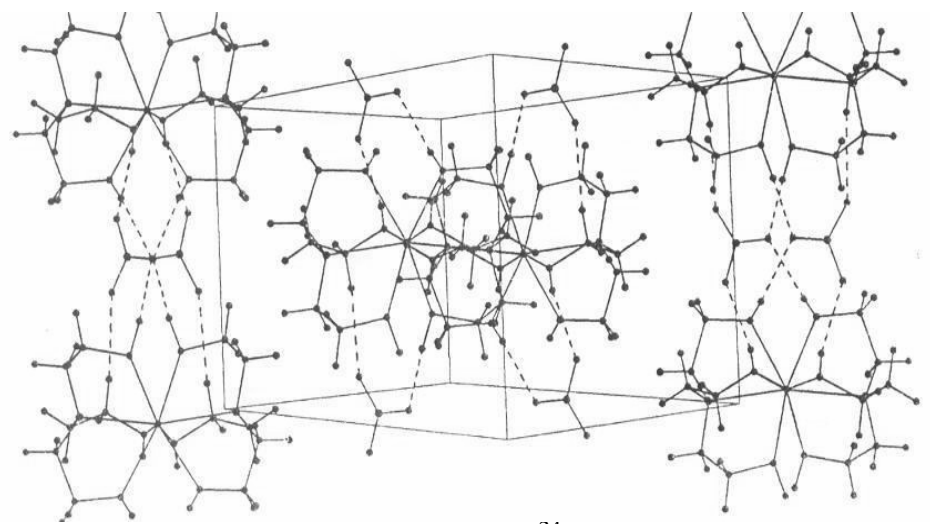

Figure 6. Unit cell of $\mathrm{Cd}^{24}$.

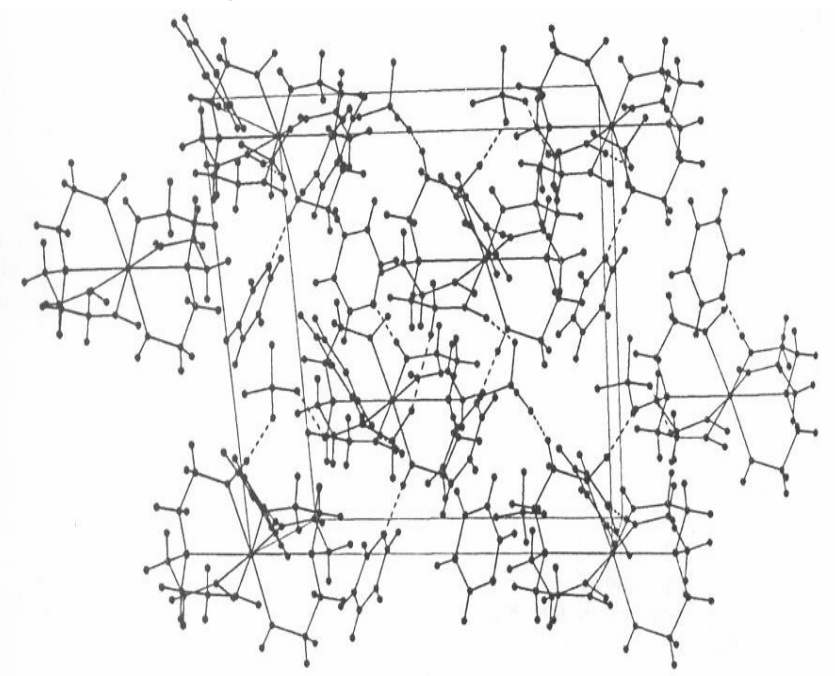

Figure 7. Unit cell of Ytterbium.

The complexes of lead, zinc and copper react with mea to form a single complex compound. All the compounds formed by cadmium with the mea and dea have coordination number three, but that the tea complexes have a coordination number of two and is seen to show stepwise complex formation. For stepwise complex formation, composition and instability constants can be found from polarographic data. The complex formation takes place via the nitrogen of the amino group. The change in the $\mathrm{pH}$ is without the significant effect on the composition of the complexes. 


\section{Thermodynamic study of mea and tea complexes with $\mathrm{Ni}(\mathrm{II})$}

The stability and thermodynamics of formation of mea complexes of Ni(II) was studied by A Ya Sychev et al. in $1962^{25}$ With bivalent metals there are two possible structures, either they resemble amines with the metal-mea bond made through $\mathrm{N}$ or an inner complex with a five membered ring is formed with the metal linked to the mea molecule through both nitrogen and oxygen. The formation of the five membered ring should lead to increase in the bond strength and therefore lead to a greater increase in enthalpy change and also to a considerably greater stability. However the results indicate that the mea is bound to the nickel solely through the nitrogen of the amino group. The stability of the mea complexes of nickel formed at $\mathrm{pH}$ 6-9 has been studied potentiometrically and the stability constants of the complexes have been calculated. Enthalpy change $(\Delta \mathrm{H})$ was measured calorimetrically and entropy change $(\Delta \mathrm{S})$ for the complexes was calculated. The addition of each successive mea to nickel leads to decrease in entropy. From comparison with other published results, it was concluded that the nickel- mea bond is made solely through the nitrogen atom. Several $\mathrm{Ni}(\mathrm{II})$ complexes of dea and alcoholic- deprotonated dea with $\mathrm{Cl}^{-}, \mathrm{Br}^{-}, \mathrm{I}^{-}, \mathrm{NCS}^{-}, \mathrm{NO}_{3}^{-}, \mathrm{ClO}_{4}^{-}$, and $\mathrm{SO}_{4}^{2-}$, as the anions have also been synthesized and analyzed by B G Sejekan et al. in $1974^{26}$. The complexes were found to be hexacoordinated involving both the bidentate and terdentate chelation by dea. This is supported by chemical analysis, conductance, magnetic susceptibility, electronic and infrared spectral studies. Three types of the complexes were prepared by mixing the ethanolic solution of dea and the $\mathrm{Ni}$ (II) salts by changing the ratios of the two. The conductance measurements were carried out for all the complexes in methanol solution. The electronic spectra of the complexes in methanol and in solid state were similar suggesting that no solvent coordination occurred in methanolic solution. The magnetic susceptibilities of the complexes were measured at room temperature. The complexes were found to be soluble in water, sparingly soluble in methanol and ethanol and insoluble in most of the organic solvents. The aqueous solutions were unstable and underwent slow hydrolysis. It is interesting to note that only dea forms a large number of complexes featuring deprotonated ligand moiety. The thermodynamics of stepwise formation of tea complexes of nickel ions have also been studied by A Ya Sychev et al. in $1963^{27}$ The change in the enthalpy during the formation of the complex was determined from the measurements of the heats of mixing of a series of nickel salt solutions and tea. The tea is unidentate in its complexes with nickel and is bonded to Ni through the nitrogen if amino group, has been verified from the values of change in entropy and change in enthalpy. The oxygen of the $\mathrm{OH}$ group in the tea does not play a part in formation of these complexes. The small value of $\Delta \mathrm{S}$ is also in agreement with the non- chelate nature of the complexes. The low values of $\Delta \mathrm{H}$ are also apparently an indication of the polar nature of the $\mathrm{Ni}$ - tea coordinate bond. The tea complexes of nickel were much less stable than the corresponding mea complexes.

\section{Reactivity and thermodynamics of aminoalcohols with Ni(III)}

In 1989 G K Reddy studied the reactivity and thermodynamics of ethanolamines with $\mathrm{Ni}(\mathrm{III})$ in aqueous solution via an inner sphere mechanism ${ }^{28}$ Thermodynamic and activation parameters have been determined and discussed. Oxidation of all the three types of ethanol amines (mea, dea and tea) is carried out at constant ionic strength and acidity. The kinetic features found were same except their reactivities with $\mathrm{Ni}(\mathrm{III})$. Oxidation of mea, dea, and tea by $\mathrm{Ni}(\mathrm{III})$ was carried out at constant ionic strength and acidity. Under the conditions when the concentration of mea, dea and tea is much greater than the concentration of $\mathrm{Ni}(\mathrm{III})$, the plot of $\log [\mathrm{Ni}(\mathrm{III})]$ v time was linear indicating unit dependence of [Ni(III)]. From such plots pseudo- first order rate constants were calculated under varying concentration of ethanolamines. In conclusion, the redox process of ethanolamines and $\mathrm{Ni}(\mathrm{III})$ which goes via an addition and elimination mechanism is simultaneously enthalpy and entropy controlled. 
Thermal decomposition of tea complexes of $\mathrm{Cr}(\mathrm{III}), \mathrm{Fe}(\mathrm{III}), \mathrm{Ru}(\mathrm{III}), \mathrm{Rh}(\mathrm{III}), \mathrm{La}(\mathrm{III})$, $\mathrm{Ce}(\mathrm{III})$, and $\mathrm{Nd}(\mathrm{III})$

Thermal decomposition of tea complexes of $\mathrm{Cr}(\mathrm{III}), \mathrm{Fe}(\mathrm{III}), \mathrm{Ru}(\mathrm{III}), \mathrm{Rh}(\mathrm{III}), \mathrm{La}(\mathrm{III}), \mathrm{Ce}(\mathrm{III})$ and $\mathrm{Nd}(\mathrm{III})$ were studied by H Icbudak et al. in the year 1996 in dynamic nitrogen and air atmosphere using TG, DTA and DTA ${ }^{29}$ The thermal decomposition takes place in three stages, while the decomposition of $\mathrm{Ce}(\mathrm{III})$ and $\mathrm{Nd}(\mathrm{III})$ complexes of tea takes place in a single stage. The final solid decomposition products were identified by $\mathrm{X}$ - ray diffraction metry. These complexes exhibit a considerable thermal stability of the order of $\mathrm{Nd}$ (III)> $\mathrm{La}(\mathrm{III}) \sim \mathrm{Ce}(\mathrm{III})>\mathrm{Cr}(\mathrm{III})>\mathrm{Fe}(\mathrm{III})>\mathrm{Ru}(\mathrm{III})>\mathrm{Rh}(\mathrm{III})$. The thermal decomposition curves of $\mathrm{Fe}(\mathrm{III})$ and $\mathrm{Ru}(\mathrm{III})$ complexes are of the following pattern (Figure 8,9$)^{29}$.

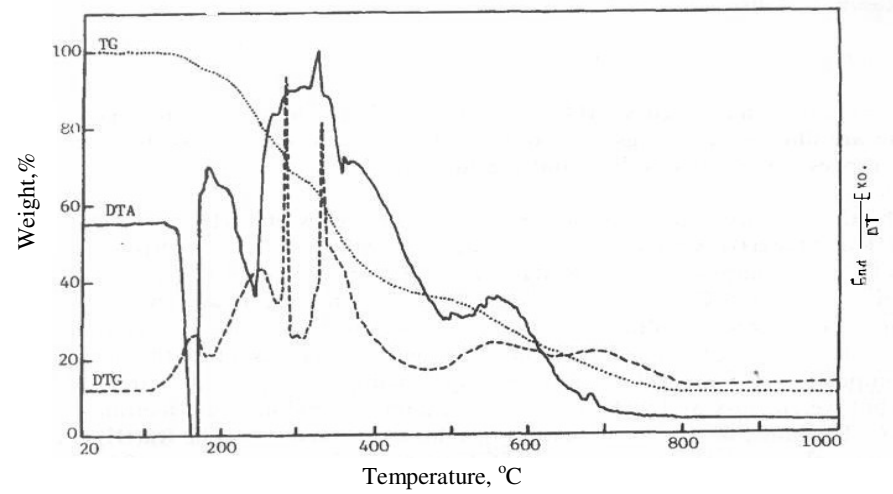

Figure 8. DTA, TG and DTG curves of $\left[\mathrm{Fe}\left(\mathrm{NTEH}_{3}\right)_{2}\right] \mathrm{Cl}_{3}$

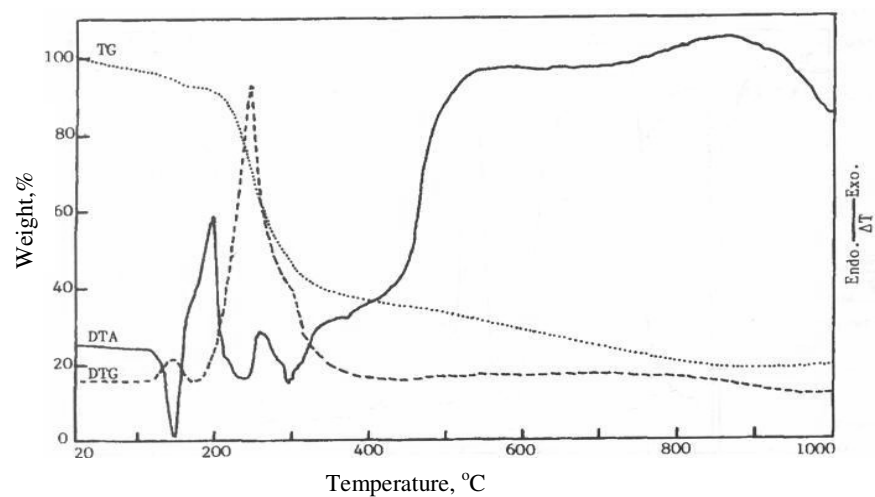

Figure 9. DAT TG and curves of $\left.\mathrm{Ru}\left(\mathrm{NT} \mathrm{EH}_{3}\right)_{2}\right] \mathrm{CI}_{3}$

Thermal decomposition behaviour of metal saccharinate complexes of $\mathrm{Cu}(\mathrm{II})$, $\mathrm{NI}(I I), \mathrm{Co}(I I), \mathrm{Zn}(\mathrm{II}), \mathrm{Mn}(\mathrm{II}), \mathrm{Cd}(\mathrm{II})$ and $\mathrm{Hg}(\mathrm{II})$ with tea

The thermal decomposition behaviour of tea complexes of $\mathrm{Cu}(\mathrm{II}), \mathrm{NI}(\mathrm{II}), \mathrm{Co}(\mathrm{II}), \mathrm{Zn}(\mathrm{II}), \mathrm{Mn}(\mathrm{II})$, $\mathrm{Cd}(\mathrm{II})$ and $\mathrm{Hg}$ (II) saccharinates with tea was studied by V T Yilmaz in the year 2002 under nonisothermal conditions by TG, DTA and DTG in dynamic nitrogen atmosphere ${ }^{30}$. Figure 10. shows the thermal decomposition pattern of Cd(II) complex of tea ${ }^{30}$. The decomposition proceeds via three main stages; the first stage involves exothermic removal of two $\mathrm{CH}_{2} \mathrm{OH}$ groups, due to degradation of uncoordinated ethanol groups of the tea molecule and the second and third stages correspond to formation of metal saccharinates and metals as the end products. Spectral and the 
thermal studies of the tea complexes of metal saccharinates show that the tea ligand behave as $\mathrm{N}, \mathrm{O}, \mathrm{O}$ - donor tridentate ligand in the metal complexes, while the sac is present as a counter ion. ${ }^{31}$ However the dimeric $\mathrm{Cu}(\mathrm{II})$ complex crystallizes as a dimethanol solvate and contains two tea ligands in a monoanionic form acting as a bridge between the two copper atoms and two sac ligands. The solid metal complexes studied are stable at room temperature and decompose progressively during heating. The thermo analytical results of tea complexes prove that the main feature is the evolution of two $\mathrm{CH}_{2} \mathrm{OH}$ groups in the first stage of decomposition, and the formation of metal saccharinates as intermediates, which decompose to the respective metals. In some cases, solid intermediates were identified with the help of IR spectrometer, however in most of the cases the intermediates could not be isolated due to overlapping decomposition steps. Hence, it was tried to assign the possible intermediates from the TG mass losses, which are reasonably consistant with the calculated values. In the year 2002, thirty eight amino alcohol complexes were prepared and analyzed in the mole ratio 1:1, 1:2 and 2:3 (M: L) by M S Masoud et $a l^{32}$ The complexes were characterized by IR, electronic absorption spectra, magnetic moment and ESR techniques. The IR spectra proved that the coordination occurs via oxygen and nitrogen atoms of the ligands. Magnetic moment values shows $\mathrm{O}_{h}$ and $\mathrm{T}_{d}$ geometry ${ }^{33-34}$. Therefore the problem of coordination of ethanolamine to metal in its complexes has not been solved and contradictory ideas have been put forward.

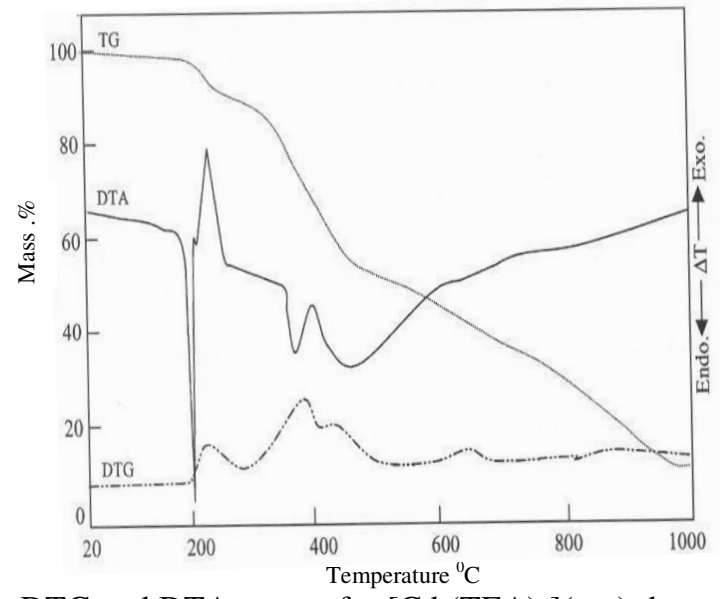

Figure 10. TG, DTG and DTA curves for $\left[\mathrm{Cd}(\mathrm{TEA})_{2}\right](\mathrm{sac})_{2}$ heated at $10^{\circ} \mathrm{C} \mathrm{min}^{-1}$ in $\mathrm{N}_{2}$

\section{Conclusion}

The study of complexation of aminoalcohols with transition metals started in 1962. Since then investigations are on. The results of $\mathrm{Ni}(\mathrm{II})$ complexation with mea, through only nitrogen reported by A Ya Sychev et al. has been modified by later studies and mea was found to behave as bidentate ligand instead of monodentate ${ }^{25}$. It has been reported that complexation of mea with $\mathrm{Cu}(\mathrm{II}), \mathrm{Co}(\mathrm{II}), \mathrm{Ni}(\mathrm{II})$ proceeds through nitrogen and oxygen and acts as a bidentate ligand. Dea with $\mathrm{Co}(\mathrm{II})$ and $\mathrm{Cu}$ (II) act as a bidentate ligand, coordinates through nitrogen and oxygen and proceeds through the formation of a dimer, while as the same ligand with $\mathrm{Ni}$ (II) and $\mathrm{Zn}$ (II) is reported to act as a bidentate ligand but with the formation of a mononuclear complex. However dea with $\mathrm{Ni}(\mathrm{II})$ is also reported to act both as bidentate and tridentate ligand. Interestingly dea with $\mathrm{Cd}(\mathrm{II})$ has been reported to coordinate through nitrogen only, hence acting as a monodentate ligand. Tea has been proved to act as a monodentate ligand coordinating through oxygen only with Thallium (III) forming binuclear complex and through nitrogen only with $\mathrm{Cd}$ (II). In the year 2002, M S Masoud et $a l^{32}$. reported that $\mathrm{Co}(\mathrm{II}), \mathrm{Cu}(\mathrm{II}), \mathrm{Ni}(\mathrm{II}), \mathrm{Cd}(\mathrm{II}), \mathrm{Hg}(\mathrm{II})$ and $\mathrm{Zn}(\mathrm{II})$ 
coordinates with all the members of amino alcohols through nitrogen and oxygen, hence acting as a bidentate ligand. The magnetic moment values proved that the complexes are of $\mathrm{O}_{\mathrm{h}}$ and $\mathrm{T}_{\mathrm{d}}$ geometry ${ }^{33-34}$. The recent study of complexation of tea with $\mathrm{Co}(\mathrm{II}), \mathrm{Cu}(\mathrm{II}), \mathrm{Ni}(\mathrm{II}), \mathrm{Cd}(\mathrm{II}), \mathrm{Hg}(\mathrm{II})$, $\mathrm{Zn}(\mathrm{II})$ and $\mathrm{Mn}$ (II) saccharinates where coordination occurs through N,O,O,' showing tea as a tridentate ligand. Hence the review shows that that the complexation of transition metals and metal complexes with aminoalcohols demands more investigation.

\section{Acknowledgements}

The authors are thankful to Prof. R.K. Wanchoo, Director, NIT, Srinagar for his support and encouragement.

\section{References}

1. Esker T, DeBoo A and Ishiwa Y, Ethanol amines CEH Report,1999.

2. Sen B and Dotson R L, J. Inorg. Nucl. Chem., 1970, 32, 2707

3. Brannon D G, Morrison R H, Hall J L, Humphrey G L and Zimmerman D N, J. Inorg. Nucl. Chem. 1971, 33, 981.

4. Bombicz P, Madarasz J, Forisz and Foch E I, Polyhedron, 1997, 16, 3601.

5. Bradley D C, Mehrotra R C and Gaur D P, Metal alkoxides London:Academic Press, 1978, pp.1-411.

6. Kesseler V G, Hubert-Pfalzgraf L Halut G S and Daran J C, J. Chem. Soc. Chem. Commun.,1994, 705.

7. Mehrotra R C and Singh A, Prog. Inorg. Chem., 1997, 46.

8. Sharma M, Singh A and Mehrotra R C, Polyhedron, 2000, 19, 77.

9. Hawkins C J and Palmer J A, Aust. J. Chem.,1978, 31,1689.

10. Lindgren T, Sillanpaa R, Nortia T and Pilhaja K, Inorg. Chim. Acta ,1983,73,153.

11. Muzzarelli R A A, 'Chitin', Pergamon Oxford ,1977

12. Micera G, Deiana S, Dessi A, Decock P, Dubois B and Kozlowski H, Inorg. Chem. Acta, 1985,107, 45.

13 Wen.Y H, Zhang $\mathrm{H} \mathrm{M}$, Qian $\mathrm{P}$, Zhou $\mathrm{H}$ T, Zhao P, Yi B L and Yang Y S Electrochemica Acta, 2006, 51, 3769-3775.

14. Paukenova A, Creager S E, Navratil J D andY Wei, J. Power Sources, 2002,109, 43.

15. Bae C H, Roberts E P L and Dryfe R A W Electrochim. Acta,2002, 48, 279.

16. Davies C WandPatel B N J. Chem. Soc. (A), 1968,1824-1828.

17. Tauler R and Casassas E, Inorg. Chem. Acta, 1986, 114 ,203-209.

18. Tauler R, Casassas E, Rainer M J A and Rode B M, Inorg.Chim. Acta, 1985, 105, 165.

19. Amirov G T, Abdullaev G K and Mamedovz Kh.S, Russ. J. Structural Chem. 1975, 16, 499.

20. Gal S, Madarasz J, Forisz E, Labadi I and Izvekov V, J. Thermal Analysis, 1998, 53, 343.

21. Karadag A, Yilmaz V T and Thoene C, Polyhedron, 2001,20, 635-641.

22. Madarasz J, Bombicz P, Czugler M and Pokol G, Polyhedron, 2000, 19, 457- 463.

23. Udupa M R, Rao V R S and Tataih G , Indian J. Chem. 1979,18A.

24. Naiini A A, Young VandVerkade J G ,Polyhedron ,1995,14, 393- 400.

25. Sychev A Ya and Gerbeleu A P , Russ. J. Inorg. Chem. vol.7 (2) 1962.

26. Sejekan B G, Udupa M R and Aravamudan G, Indian J. Chem. ,1974, 12, 533-534

27. Sychev A Ya, Gerbeleu A Pand Migal P K, Russ. J. Inorg. Chem., 1963, 8(9), 3081-3083.

28. Reddy G K, Reddy T R and Jagannadham V ,Indian J. Chem. 1989, 28 A 32-35.

29. Icbudak H , Yilmaz V T and Olmez H ,Thermochimica Acta, 1996, 289 23-32.

30. Karadag A, Yilmaz V Tand Topcu Y ,Thermochimica Acta, 2002, 383, 129- 135.

31. Topcu Y, Andac O, Yilmaz V T and Harrison Y T A ,Acta Crystallogr. 2001, E57, m82

32. Masoud M S, El-Eneim S A Abou, Abed I M and Ali A E, J. Coord. Chem. 2002, 55, 153.

33. Morassi R, Bertini I and Sacconi L ,Coord. Chem. Rev., 1973, 11, 343.

34. Kirelson D and Neiman R, J. Chem. Phys. 1961, 35, 149. 


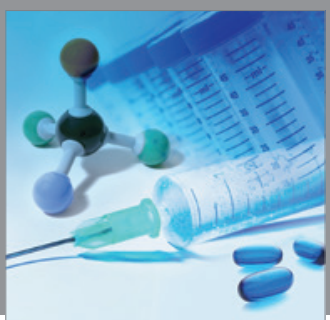

International Journal of

Medicinal Chemistry

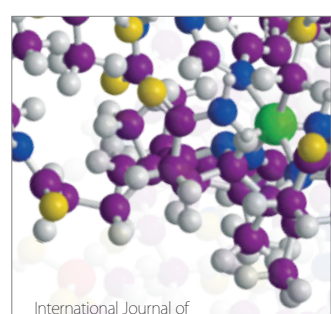

Carbohydrate Chemistry

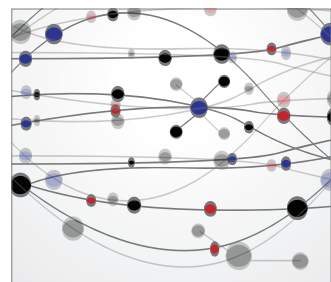

The Scientific World Journal
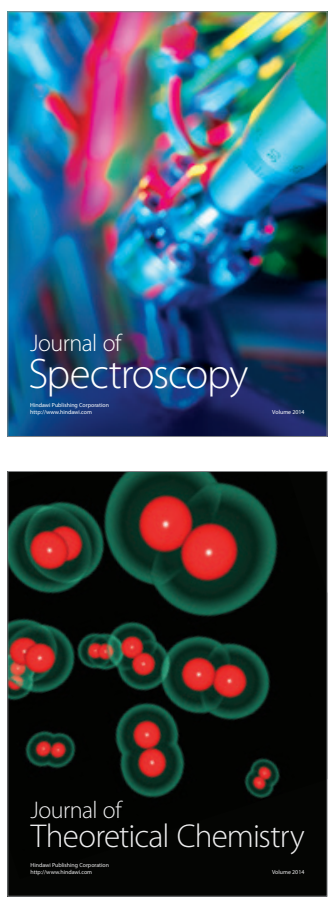
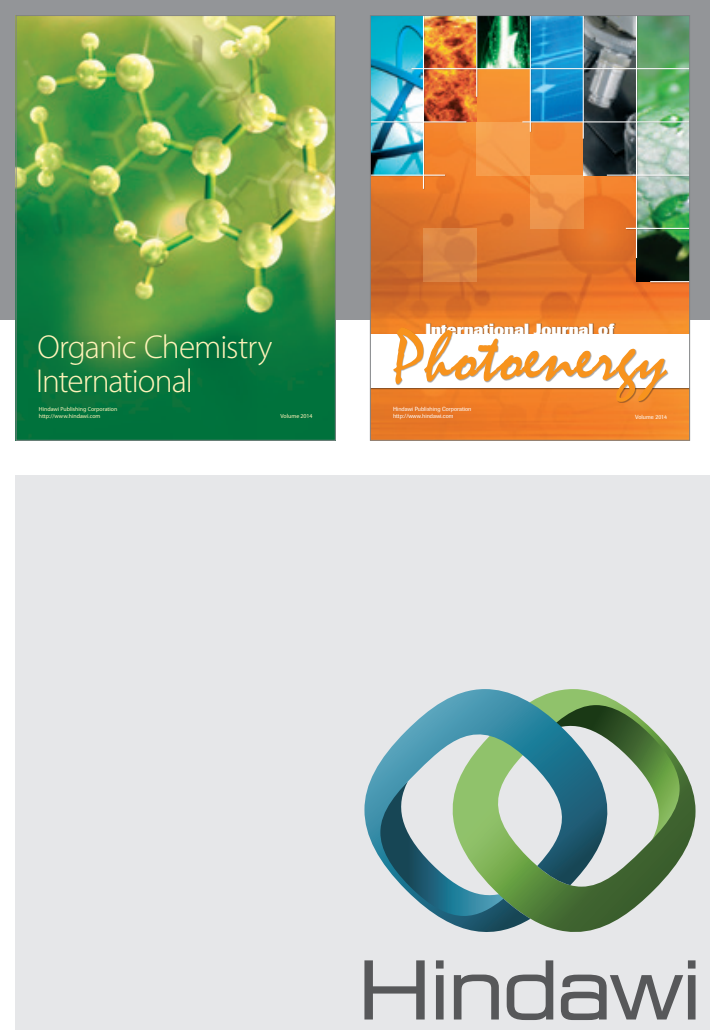

Submit your manuscripts at

http://www.hindawi.com
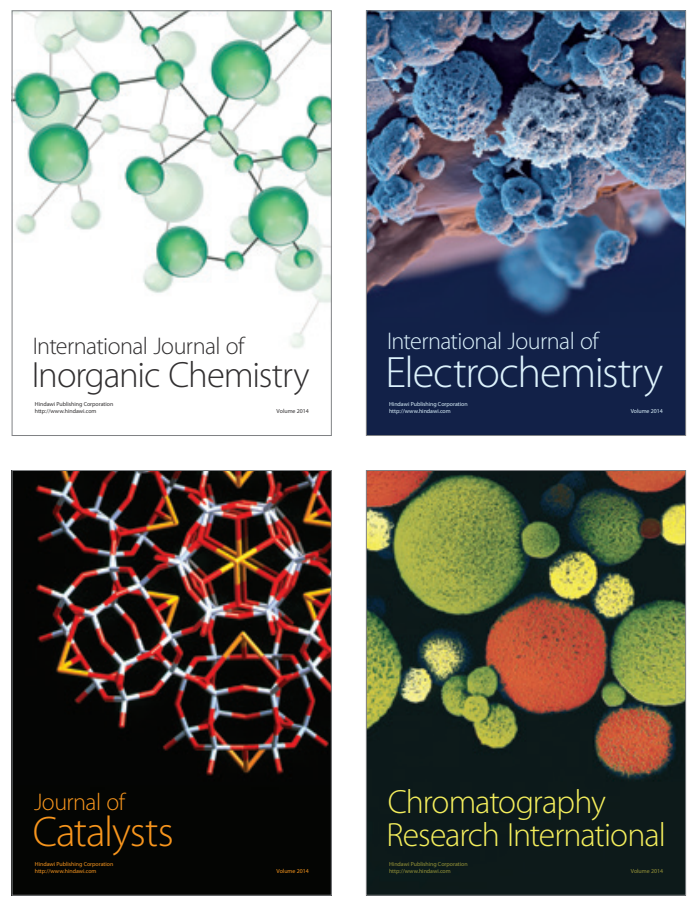
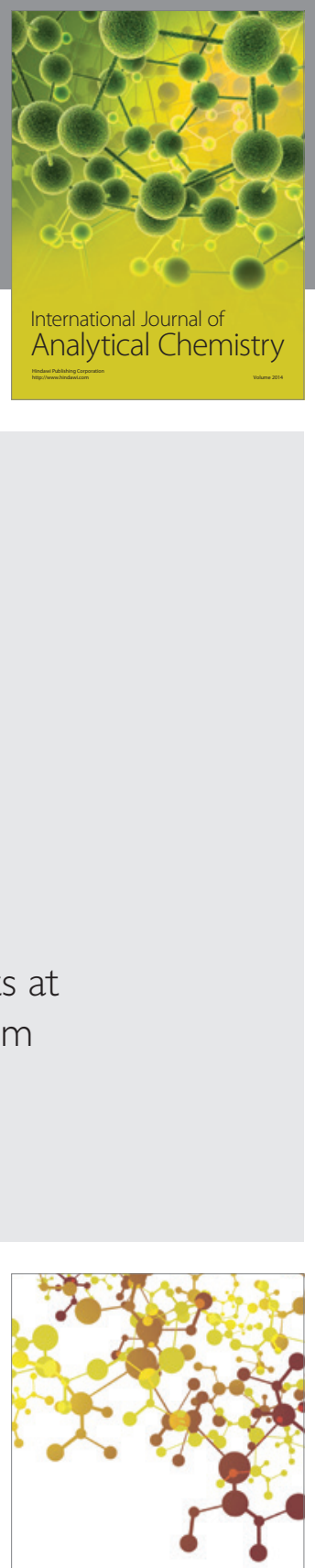

Journal of

Applied Chemistry
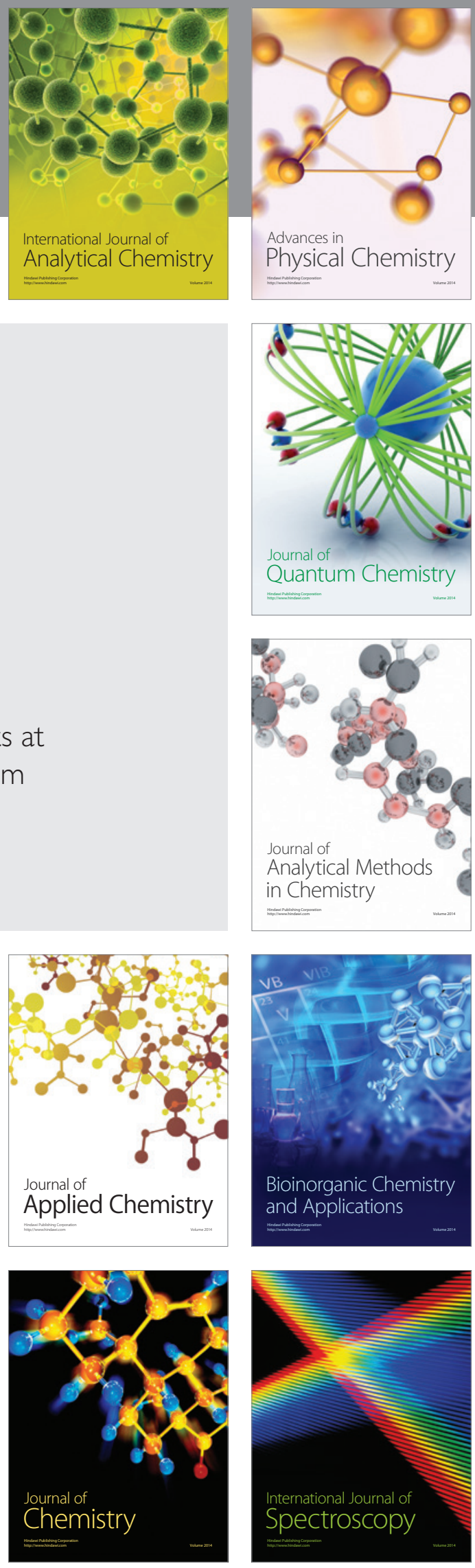